\title{
Epizootic situation of Aujeszky's disease within the territory of the Republic of Kazakhstan
}

\author{
Zhumagali K. Koshemetov ${ }^{1}$, Zhanat B. Kondibayeva2 ${ }^{2 *}$, Assilbek M. Mussoyev ${ }^{3}$, Abdikalyk A. Abishov ${ }^{4}$ \\ and Urzhan Zh. Omarbekova ${ }^{3}$ \\ ${ }^{1}$ Laboratory of Diagnostic of the Infectious Diseases, Research Institute of Biological Safety Problems, Gvardeiskiy, \\ Republic of Kazakhstan \\ ${ }^{2}$ Laboratory for Technologies of Cultivation of Mickroorganisms, Research Institute of Biological Safety Problems, \\ Gvardeiskiy, Republic of Kazakhstan \\ ${ }^{3}$ Department of Biological Safety, Kazakh National Agrarian University, Almaty, Republic of Kazakhstan \\ ${ }^{4}$ Department of Virology, LTD "NPC DiaVak-ABN", Almaty, Republic of Kazakhstan
}

\begin{abstract}
Background: The relevance of the study is determined by the danger that this disease poses to all types of domestic animals in the Republic of Kazakhstan, as well as the significant damage caused by this situation to the entire agriculture of the Republic of Kazakhstan. Timely and competent analysis of the epizootic situation for this disease in the country will reliably determine the development tendencies of this condition and predetermine a set of measures that should be taken to combat this animal disease in agricultural regions of the Republic of Kazakhstan.

Aim: This study examines the development of the epizootic situation of Aujeszky's disease within the territory of the Republic of Kazakhstan.

Methods: To achieve the set research goal, a combination of quantitative and qualitative research methods are used.

Results: The results of this research article can be of significant importance for livestock breeders in the Republic of Kazakhstan, who are working on raising the number of pigs and other types of domestic animals and are interested in a further increase in the number.

Conclusion: From a practical standpoint, the significance of this study is conditioned by the possibility of searching and determining the main directions of the spread of the disease under consideration in agricultural lands and regions of the Republic of Kazakhstan, as well as taking a set of measures to eradicate such a disease and prevent its future occurrence in the country.

Keywords: Agriculture of Kazakhstan, Epidemiological situation, Livestock of domestic animals, Livestock sector.
\end{abstract}

\section{Introduction}

Aujeszky's disease refers to infectious, acute diseases that affect almost all, without exception, domestic and wild animals. Symptoms of the disease are manifested in the central nervous system damage, the development of inflammatory processes in the lungs, and its course is accompanied by itching, fever, and scratching. In domestic animals, this disease occurs in almost all countries of the world. The causative agent is a viruscontaining deoxyribonucleic acid (DNA) and belonging to the Herpesviridae family, genus Varicellovirus. Sulfonamides and antibiotics do not significantly affect the virus. Almost all domestic and wild animals are susceptible to this virus. Domestic pigs and piglets under 8 weeks of age are most susceptible to the virus (Aujeszky's Disease) (Morbus Aujeszky, 2019).

The agriculture of the Republic of Kazakhstan has repeatedly been exposed to a dangerous situation associated with the emergence and spread of Aujeszky's disease in the region. Back in 2012, the Minister of Agriculture of the Republic of Kazakhstan issued a decree defining a mandatory list of animals subject to decontamination and processing without withdrawal of products and raw materials that are of animal origin (Decree of the Minister of Agriculture, 2012). As of February 2009, according to the newspaper "Kazakhstan Today", more than 120 heads of cattle, as well as 65 heads of small ruminants, had died from Aujeszky's disease specifically in the farm of the Karaganda region, and the corpses of the animals were burned. This confirms the severity of the epizootic situation of Aujeszky's disease in the territory of the Republic of Kazakhstan in general and in the Karaganda region in particular.

According to the data from the Veterinary Control and Supervision Committee of the Ministry of Agriculture of the Republic of Kazakhstan as of February 22, 2018, outbreaks of Brucellosis in local residents and Aujeszky's disease among livestock were noted in the Akmola region of the Republic of Kazakhstan. Residents of the village of Doroginka in the Akmola region carried out complete disinfection of their

*Corresponding Author: Zhanat B. Kondibayeva. Laboratory for Technologies of Cultivation of Mickroorganisms, Research Institute of Biological Safety Problems, Gvardeiskiy, Republic of Kazakhstan. Email: kondibayeva5496@kpi.com.de 
houses to prevent the development of the disease and eliminate the further possibility of the spread of diseases (Epizootic Situation, 2018). The epizootic situation of the Aujeszky's disease in the territory of the Republic of Kazakhstan is all the more serious because agriculture in the country remains an important sector of the economy (Agriculture of the Republic of Kazakhstan, 2020).

This year, the epizootic situation in Kazakhstan remains generally stable. There are no sharp outbreaks of diseases in domestic animals in the Republic, only isolated cases are observed. From the beginning of the year to May, there were about 80 cases of infectious diseases of domestic animals and cattle. The Minister of Agriculture of the Republic of Kazakhstan, Saparkhan Omarov, noted that of the diagnostic research activities planned for the current 2020 year, approximately $90 \%$ have been completed, while out of the 150 million procedures planned in the republic for the year to vaccinate domestic animals against infectious diseases, approximately $97 \%$ of the plan has been completed. The proportion of planned vaccinations to prevent Aujeszky's disease in pets amounts approximately to $20 \%$ (Sarmurzina et al., 2017; Brazhko et al., 2019; Vaal, 2020).

The purpose of this article is to examine the development of the epizootic situation of Aujeszky's disease in the territory of the Republic of Kazakhstan.

A review of literary sources covering the issues of the epizootic situation of Aujeszky's disease in the territory of the Republic of Kazakhstan yields the following results. Assessing the overall impact of the diseasecausing virus on humans and animals, Salinas-Zacarias et al. (2020) noted: "New-born people and animals are very sensitive to viral infections. Aujeszky's disease virus (ADV) is a porcine herpesvirus 1 that infects the respiratory tract and is fatal during the first weeks of life." Furthermore, the researchers note the difficulties in the approach to vaccination against this virus: "Modern intramuscular vaccines used at weaning, cause weak mucosal immunity and are often unable to prevent and control the disease. Moreover, early vaccination has not been thoroughly studied". The seriousness of this situation is also emphasised by other researchers. In particular, Vrublevskaya et al. (2017a) addressed the difficulties in developing a vaccine against the ADV. Describing the results of their studies, the authors wrote: "A direct sidestream assay of double antibodies (DDA-gB-LFA) was developed to detect antibodies against the glycoprotein $\mathrm{B}(\mathrm{gB})$ of ADV in porcine serum. Native ADV gB was used to obtain a conjugate with colloidal gold particles and immobilisation on a strip membrane. GB, purified from ADV virions by immunoaffinity chromatography, retained its native epitope structure after adsorption on a nitrocellulose membrane and the surface of colloidal gold particles. The diagnostic specificity and sensitivity of DDA-gB-LFA were evaluated with the use of 236 field porcine sera".
According to Cheng et al. (2020), there is difficulty in developing a vaccine against the ADV that largely determines the difficulties in assessing the epizootic situation of this disease. At the same time, several Internet publications noted the stability of the epizootic situation for Aujeszky's disease in the Republic of Kazakhstan at large. "In 2017, compared with 2016, there is a $4 \%$ decrease in the total number of foci of diseases especially dangerous for domestic animals" (Epizootic Situation, 2018), and in March 2018, a veterinary and sanitary treatment of livestock was scheduled, starting from the southern regions of the country. Measures included the diagnosis of infectious diseases of domestic animals (including Aujeszky's disease) and vaccination against them (Lefkowitz et al., 2018). At the same time, scientists were actively looking for additional opportunities for diagnosing the disease, creating the necessary conditions for highquality vaccination of domestic animals.

Thus, a group of researchers (Vrublevskaya et al., 2017b) conducted a series of studies aimed at developing an assay for the detection of antibodies specific to the Aujeszky's virus glycoprotein. The study concluded that: "The developed pCDAS-gB-LFA is a fast, sensitive, and specific method for detecting antibodies to ADV gB and can be used to screen ADVinfected pigs in unvaccinated herds". Thus, modern science attaches great importance to identifying new ways of detecting domestic animals infected with the $\mathrm{ADV}$ so as to prevent the development of an epidemic due to the disease.

\section{Materials and Methods}

This study aims to assess the epizootic situation of Aujeszky's disease in the territory of the Republic of Kazakhstan. The main factors influencing the situation are identified and stated, the degree of danger of Aujeszky's disease for the livestock sector of the Republic of Kazakhstan was assessed. The authors describe the measures designed to limit the disease and prevent the possibility of its occurrence and development. The methodology of this study is based on a combination of qualitative and quantitative research methods, based on an analysis of the facts collected during the study of the epizootic situation of Aujeszky's disease in the Republic of Kazakhstan in general and the study of the virus causing it in particular. All information available on this issue were thoroughly analysed, including publications in Internet journals, research by authors investigating the development of an effective vaccine against the mentioned disease, as well as information from official sources on this issue. A large volume of the studied information contributed to its better understanding and in-depth analysis, as a result of which conclusions are drawn as to the causes of Aujeszky's disease in the agricultural sector in the Republic of Kazakhstan and the methods and techniques of combating the virus that 
causes this disease. A significant amount of data was taken from publications in foreign sources covering the study of the virus that causes this disease, and methods to combat its spread.

Besides, the study provides a significant amount of statistical data on the nature of the virus that causes Aujeszky's disease in animals in the territory of the Republic of Kazakhstan. All statistical information are clearly structured and presented in strict accordance with the subject matter and purpose of this study. In the course of this paper, an exploratory assessment is provided for all the factors affecting the occurrence and spread of Aujeszky's disease in Kazakhstan and specifically in certain regions of the country. The impact of this virus at large on the epizootic situation in the region considered for this research article is also assessed. In general, the results of the research carried out can be of significant importance in the context of preparing future forecasts of the development of the epizootic situation of Aujeszky's disease in the Republic of Kazakhstan and can serve as a real example for predicting the development of the situation associated with this disease in other countries (Allepuz et al., 2008; Paes et al., 2013; Shamshedenova et al., 2019).

The chosen research methodology is extremely important since it allows to most objectively assess the number of materials selected for research and the final quality of their investigation. In the future, this factor can play a significant part in the analysis of subsequent developments on similar topics carried out with consideration and the use of a similar research methodology. The epizootic situation in Kazakhstan and Asian countries associated with Aujeszky's disease and not related to it regularly changes, which requires additional research on this issue with the choice of a methodology that best meets the needs and objectives of this study. In general, the materials and methods of this study fully meet the set task of collecting and analysing the data necessary for a qualitative resolution of the task.

\section{Results}

\section{History of the spread of Aujeszky's disease}

Upon analysing the epizootic situation in the former USSR from 1951 to 1990, it was established that for 40 years the disease was registered annually. Over 40 years, 620,037 pigs were diseased, of which about 260,000 died (Decree of the Minister of Agriculture, 2012). In 1984-1986, Aujeszky's disease was registered among pigs in the North Kazakhstan, Akmola, Pavlodar, and Turgai regions. In 1987-1988, the disease was noted among fur-bearing animals in the Mezhleskhoz animal farm of the Semipalatinsk region, where 13 minks were diseased and three died. In 1988, 39 foxes were diseased in the Zyryanovsky district of the East Kazakhstan region, five of them died from Aujeszky's disease. In 1991, the disease was noted in the Semipalatinsk region, where two heads of cattle were diseased and died. In the same year, outbreaks of Aujeszky's disease were registered in Zhambyl, North Kazakhstan, Semipalatinsk, Akmola, East Kazakhstan, Pavlodar, and Ust-Kamenogorsk regions.

In March 1992, the Research Institute of Biological Safety Problems (RIBSP) received a message from the Zhambyl Regional Veterinary Department about the disease of calves on the Gorky collective farm in the Zhuvalinsky district: 32 were ill and 11 calves aged 2-4 months died. According to clinical signs, the disease was described by excitability, impaired coordination of movement, and seizures in animals; profuse salivation was noted in some calves. The disease lasted 5-7 days and ended with the death of the animals. In RIBSP, a study of the pathological material delivered from the Zhuvalinsky district was carried out to establish a diagnosis.

To isolate the causative agent of a viral nature, samples of pathological material were infected with cultures of cells of the nucleus pulposus, the precursor cell of T lymphocytes (PT), the kidney of the guinea pig embryo (SPEV), and the kidney of the embryo of the Syrian hamster (VNK-21). On days 2-3, a viral agent was isolated in all cultures, which caused cytopathic changes inherent in the ADV. To identify the isolated pathogen, rabbits were infected with samples of pathological material and the cultured virus, which were diseased on days 3-5 and died with clinical signs inherent in the Aujeszky's disease. As a result of the virus identification by means of infecting rabbits with pathological material and a culture virus, it was established that the cause of the disease and death of calves on the Gorky farm was the Aujeszky's disease. In 1994, the Aujeszky's disease was registered in the Akmola region among suckling piglets, where seven piglets were diseased in 4 days, of which three died. In 1996, cases of mass illness with the death of suckling and weaning piglets without any clinical signs and pathoanatomical changes were detected on the pig farm of the Ak-Bulun in the Kordai district of the Zhambyl region. 300 piglets were diseased, of which 106 died (Fig. 1).

The death of dogs fed with the corpses of dead piglets was also noted, and the corpses of rats were found on the pig farm (hence the "Kordai" strain was isolated from a pig in the territory of the Republic of Kazakhstan). According to the Ministry of Emergency situations, the last case of animals infected with Aujeszky's disease was registered on January 30, 2009, in the Karaganda region among farm animals from an owner-operated farm. Therewith, the disease most of all affects pigs, especially young ones, fur-bearing animals, and cattle. The reservoir of infection were most likely rats from livestock facilities. For several years in the Republic of Kazakhstan, plans have been drawn up for antiepizootic measures to prevent and eliminate especially dangerous diseases of farm animals. The basis of these measures is 


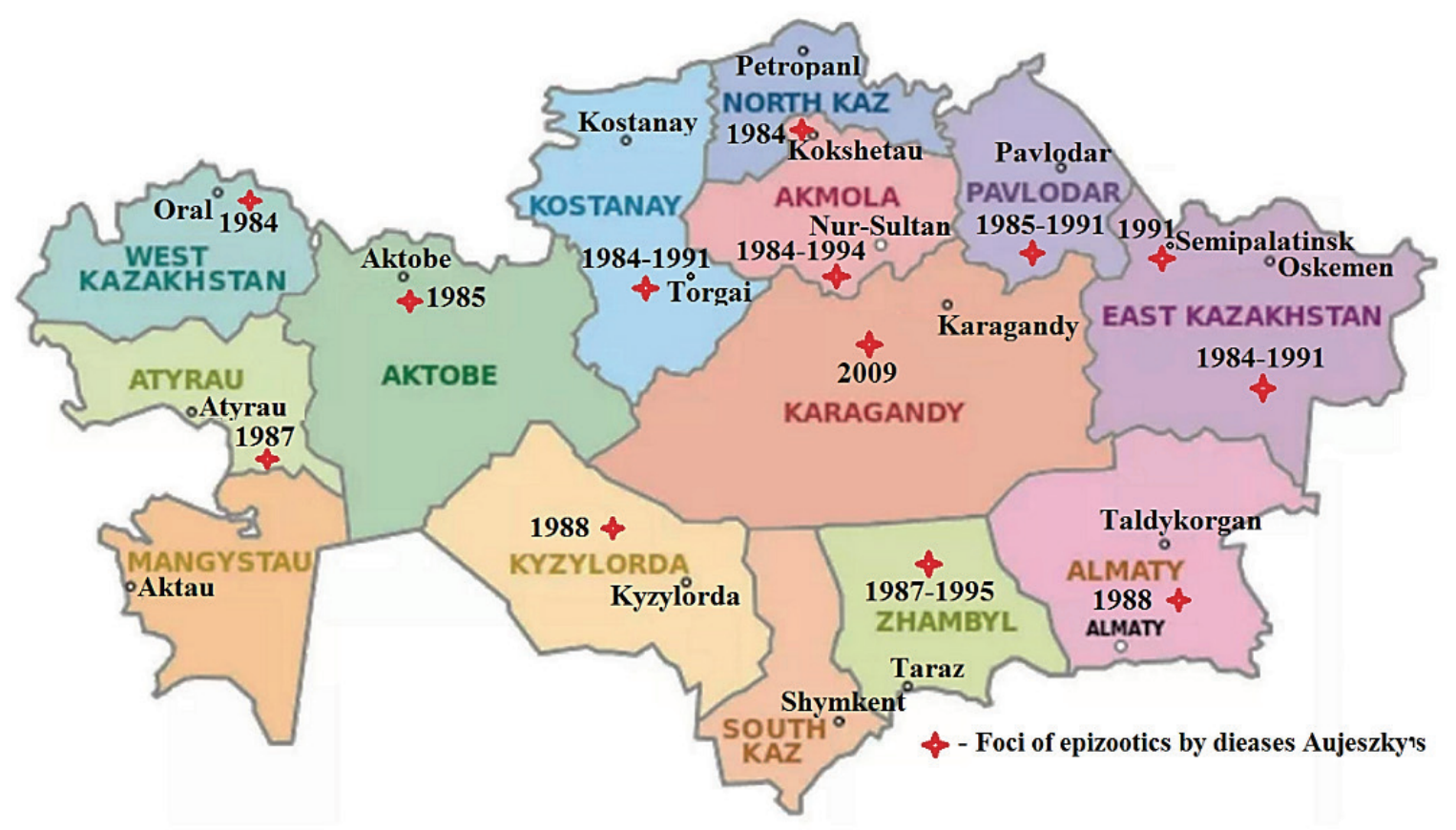

Fig. 1. Distribution of Aujeszky's disease in the territory of the Republic of Kazakhstan in the period from 1984 to 2009.

in compliance with veterinary and sanitary requirements for the prevention and elimination of infectious diseases in the Republic of Kazakhstan.

Modern trends in the development of Aujeszky's disease and its elimination in the Republic of Kazakhstan

The epizootic situation of Aujeszky's disease in the territory of the Republic of Kazakhstan at the moment, according to official sources, remains stable and is fully controlled by the government of the country and the authorities responsible for the sanitary and epidemiological situations. Nevertheless, the risk of the emergence and development of Aujeszky's disease in the country remains, which can potentially change the general epizootic situation in the Republic of Kazakhstan at any time.

Figure 2 graphically shows the curve of the incidence of Aujeszky's disease in cattle in the Republic of Kazakhstan over the past 4 years. The graph clearly demonstrates the decline in the disease curve due to measures taken by the government to prevent the development of this disease and maintain the epizootic situation in the country at a stable, controlled level. This is facilitated by timely and clear actions carried out by the population to decontaminate the territory and prevent outbreaks of the disease in private farms and at state enterprises in the livestock sector of agriculture in Kazakhstan. For the period from 2017 to 2020, the incidence of cattle, according to official information, decreased more than six times - from 120 cases in 2017 to 17 registered cases in 2020. This statistical trend emphasises the effectiveness of measures taken in the country to control the epizootic situation and prevent its development. The agricultural sector of the Republic at large remains successful in terms of control over the epizootic situation in the country and the incidence of Aujeszky's disease. The situation is fully controlled and remains stable and predictable.

Figure 3 graphically shows the curve of the incidence of pigs with Aujeszky's disease in the Republic of Kazakhstan over the past 4 years. The downward tendency in the number of diseases continues, as in the situation with cattle. The reasons for the decrease in the incidence, as in the previous case, lie in the timely measures that were taken to identify and suppress cases of pig diseases in the Republic of Kazakhstan, as well as in the implementation of a series of proactive measures to prevent the incidence. In combination, all these measures had a positive effect on the general epizootic situation in the country in relation to this specific disease. The danger of the emergence and development of an epizootic situation of Aujeszky's disease within the territory of the Republic of Kazakhstan is caused by high rates of virus carriage, which lasts up to 25 years and even more.

The abrupt onset and manifestation of symptoms of the disease is also dangerous. Previously, ill animals may well become sources of infection, which increases the danger of this disease. Also, the danger lies in the incubation period of the disease, which is $2-5$ days, in the course of which the potential carrier of the infection is in direct contact with other animals and can become a source of infection for them. The animal starts to itch, and aimlessly runs around and rushs at its fellows, inflicting injuries and scratches on them. In 


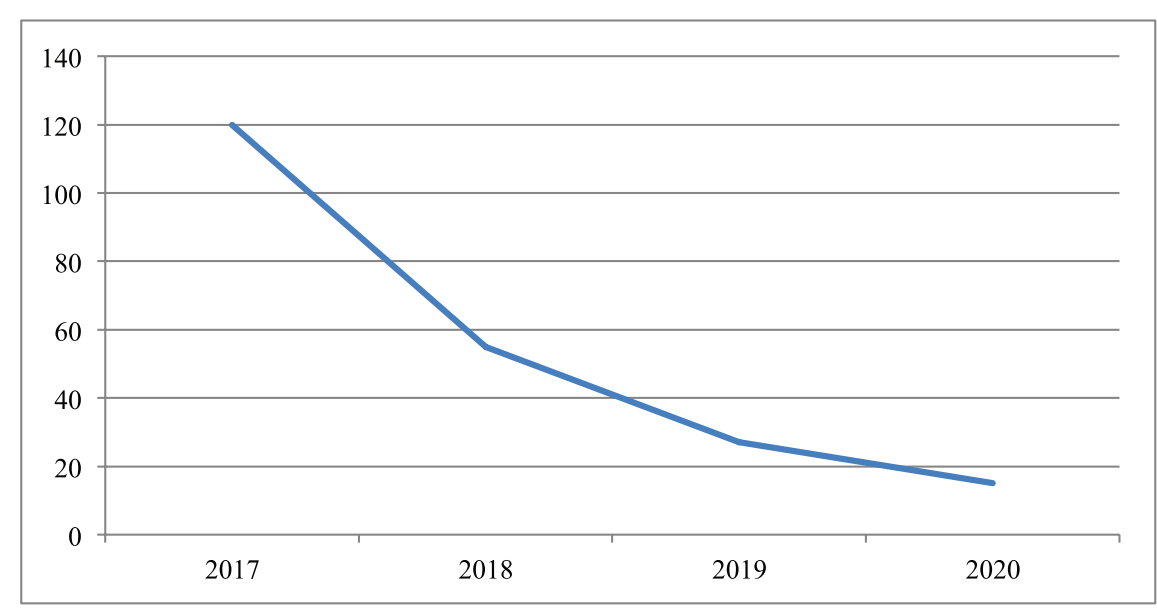

Fig. 2. Incidence of Aujeszky disease in cattle in the Republic of Kazakhstan (2017-2020).

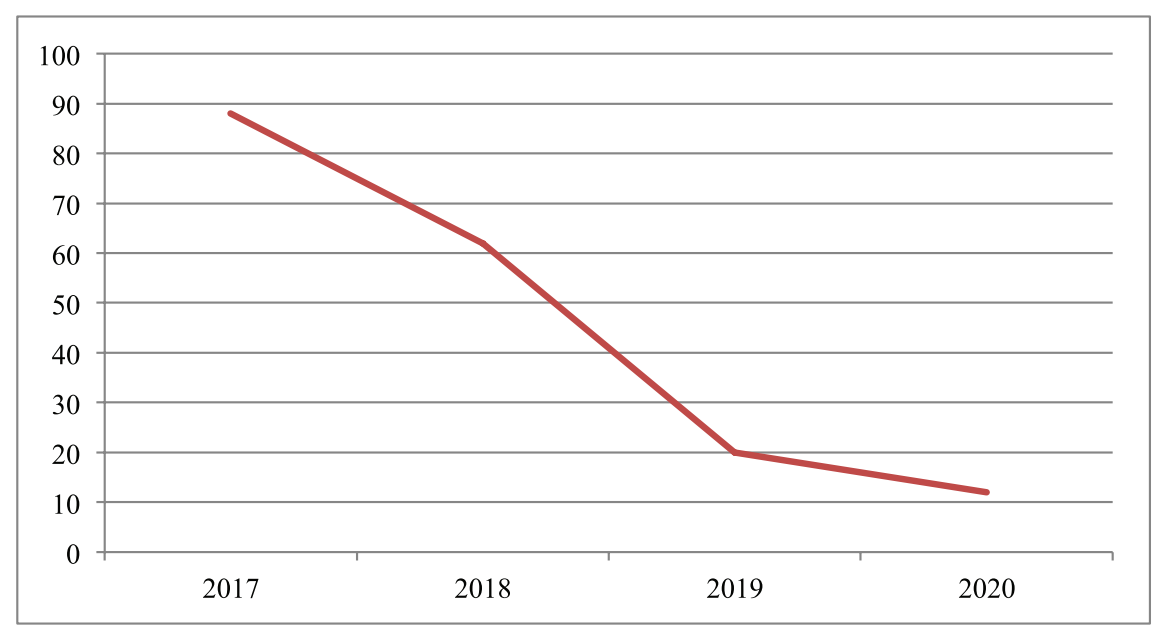

Fig. 3. Incidence of Aujeszky disease in pigs in the Republic of Kazakhstan (2017-2020).

this context, it seems appropriate to introduce a set of measures provided below to prevent infection with the virus that causes the disease and the development of the disease itself:

Compulsory vaccination of domestic animals, especially piglets under 8 weeks of age, that are especially susceptible to this viral infection;

Timely informing the population about the symptoms of Aujeszky's disease and methods of combating it; At the first symptoms, obligatory performance of differentiation of Aujeszky's disease from suspected rabies;

Isolation of an animal showing signs of the disease from its fellows;

Timely disposal of meat of dead or slaughtered domestic animals, which, in a rotten state, constitutes a potential source of infection;

The imposition of quarantine measures on the entire farm where symptoms of Aujeszky's disease were found in pets.
For sick animals, there are no specific treatments for Aujeszky's disease. The simultaneous use of antibiotics and vitamin-containing preparations ensure the prevention of the development of infection in the affected animal. The danger is that even after recovery, it will continue to be a potential virus carrier.

According to the data presented in Table 1, a comparative analysis of the situation of Aujeszky's disease among cattle in Kazakhstan with other countries shows a relatively favourable epizootic situation in the Republic. In the agriculture of Kazakhstan, the most favourable epizootic situation for Aujeszky's disease takes place in relation to cattle. The most difficult situation is observed in Russia, where there are difficulties in preventing the development of the disease. To date, there is a stability of the epizootic situation in the Republic of Kazakhstan. Despite isolated outbreaks of Aujeszky's disease in pigs, over the past months of 2020, there are no signs that may indicate a serious risk of reoccurrence and spread of 
Table 1. The number of reported cases of cattle with Aujeszky's disease in Kazakhstan compared with other countries (2017-2020).

\begin{tabular}{ccccc}
\hline \multirow{2}{*}{ Country } & \multicolumn{4}{c}{ Year } \\
\cline { 2 - 5 } & $\mathbf{2 0 1 7}$ & $\mathbf{2 0 1 8}$ & $\mathbf{2 0 1 9}$ & $\mathbf{2 0 2 0}$ \\
\hline Kazakhstan & 120 & 57 & 25 & 17 \\
Russia & 322 & 117 & 220 & 286 \\
\hline Uzbekistan & 25 & 74 & 77 & 58 \\
\hline Kyrgyzstan & 11 & 12 & 17 & 22 \\
\hline
\end{tabular}

this dangerous disease in the agricultural lands of the Republic of Kazakhstan. According to the Minister of Agriculture of Kazakhstan, Saparkhan Omarov, all regions of the republic are currently provided with the necessary veterinary preparations by more than $97 \%$ of the declared annual need (Vaal, 2020; Uzakov et al., 2020).

At the same time, the minister noted that in the procurement of preparations, preference is given to products of domestic manufacturers over foreign supplies. Preparations have been made to open additional inspection stations for testing livestock for the virus that causes Aujeszky's disease in domestic animals. All routine procedures for vaccinating livestock to prevent the onset and development of Aujeszky's disease in the Republic of Kazakhstan are carried out in full accordance with the previously devised plan (Boadella et al., 2012; Tazitdinova et al., 2018). As a result of the comprehensive measures undertaken by the government and implemented locally to prevent the occurrence and timely suppression of Aujeszky's disease among pigs and cattle and small ruminants, the Republic of Kazakhstan received the official status of a prosperous region with regards to an entire set of livestock diseases, including Aujeszky's disease. Measures are regularly carried out to identify causes of diseases, to eliminate them, and to prevent the reoccurrence of such disease in the future.

\section{Discussion}

The issues of the epizootic situation of Aujeszky's disease in general and in the Republic of Kazakhstan, in particular, receive a timely, qualitative assessment of researchers working in this direction, and journalistobservers engaged in researching issues, directly and indirectly, related to this disease of livestock. Numerous authors emphasise the seriousness of the situation with the spread of Aujeszky's disease in agricultural regions of any country. In particular, Christensen and Vallières (2016), considering the possible scenarios for the onset and spread of Aujeszky's disease among pigs in Canada, have noted that "there are three levels of freedom from diseases that pose a threat to livestock in any country. A country may be recognised as a 'relatively free', 'officially free', or it may be required to regularly report cases of the disease in livestock. In general, 'free from pet disease' is a relative concept and can have different meanings for science and trade" (Christensen and Vallières, 2016). Thus, the researchers emphasise the ambiguity of assessing the complexity of the epizootic situation in the country, as exemplified by Canada. In turn, Silva-Junior et al. (2020), upon investigating the early diagnosis of Aujeszky's disease with the use of state-of-the-art diagnostic methods, point to the fact that "The main methods of controlling Aujeszky's disease include vaccines with the deleted gene SHV1 $\mathrm{gE}$ and ELISA for detecting specific $\mathrm{gE}$ antibodies in infected animals, distinguishing infected animals from vaccinated animals". This study points out the need for early diagnosis of diseases in domestic animals to determine the most effective methods to combat the existing disease and prevent its further spread.

As for Kazakhstan, according to official sources, the situation in the country this year is generally stable and controlled. The dynamics of the growth of cases of Aujeszky's disease in the Republic of Kazakhstan tends to decrease, thanks to the timely government measures and the activity of the rural population toward solving this issue. As of July 2020, cases of Aujeszky's disease in pigs and cattle and small ruminants in the country did not exceed a total of 100-120 (Vaal, 2020). At the same time, studies by authors from other countries on preventing the spread of Aujeszky's disease in other regions and the methods used to combat this disease are of great interest. Thus, a group of researchers (Liu et al., 2019), considering the experience of suppressing the spread of Aujeszky's disease among domestic animals in China, wrote: "Pseudorabies of pigs (Aujeszky's disease) can lead to serious losses for farm owners and even the entire pig industry, causing infertility, abortion, and stillbirth in breeding sows, as well as diarrhea, respiratory failure, and death in piglets. The pseudorabies virus could be prevented, controlled, and eradicated by clean-up at the farm and regional level through rigorous vaccination, quarantine, diagnosis, elimination of positive animals, and care for healthy animals". Thus, the researchers indirectly confirm the regularity and timeliness of measures taken by the government and the population of the Republic of Kazakhstan for the qualitative prevention of the onset and development of Aujeszky's disease in the territory of the country's agricultural land. Burdinskaya (2013) noted that "In general, the virus that causes Aujeszky's disease affects the cattle population between $3 \%$ and $60 \%$ of the livestock unless urgent measures are taken to stop its spread. In carnivores and ruminants, when a virus enters their body, they often suffer from the central nervous system damage. These animals die within a very short time". In this context, the development of a high-quality vaccine against the ADV and its timely application are of great importance.

A group of researchers (Pomorska-Mól et al., 2018) were engaged in the scientific development of such 
a vaccine. According to the results of the work " 40 pigs were used [control, not vaccinated (C), control vaccinated $(\mathrm{CV})$, vaccinated, received enrofloxacin (ENRO)]. From day 1 to day 3, pigs from the ENRO group received enrofloxacin at the recommended dose. Pigs from the ENRO and CV groups were vaccinated twice against the ADV. There was a significant delay in the development of humoral response in pigs receiving a dose of enrofloxacin compared to the $\mathrm{CV}$ group. Furthermore, the ENRO group showed a significant decrease in IFN- $\gamma$ production and significantly lower stimulation index values after re-stimulation with ADV compared to the CV group. The secretion of IL-6, IL10 , and TNF- $\alpha$ by PBMCs after stimulation of recall was also affected in the ENRO group. The results show that enrofloxacin, apart from its antimicrobial properties, has significant immunomodulatory effects and can alter the immune response to vaccines".

Thus, studies show broad prospects in the development of a special vaccine that can qualitatively fight the emergence and development of the ADV in pigs. In general, the issues of Aujeszky's disease and the related epizootic situation in the Republic of Kazakhstan and other countries are far from ambiguous and require assessment with consideration of the experience of various researchers. A comparison of their scientific developments will facilitate a better understanding of this issue and open up additional research opportunities. An additional study was conducted to assess the epizootic status of the province of Vojvodina in terms of the occurrence of MA in different species of domestic and wildlife, possible routes of infection, and spread through the sea. The role of various biosecurity measures in the prevention and control of MA outbreaks was also studied. The results of our investigation revealed that the swine population in the Vojvodina region is enzootically infected with MA and that infection was detected in six different animal species, sporadically or in enzootic form. The single most important factor for MA occurrence was the localization of the farm in the high-density pig population regions. Poor biosecurity measures to prevent the entry of the virus and lack of appropriate measures to stop the spread of the infection within the herd were also identified. The direct contact with pigs or ingestion of raw and poorly cooked swine products was the estimated route of infection for all other affected animals except three dogs.

We investigated nine large commercial farms for biosecurity measures and management practices. Seven of these nine farms suffered MA outbreaks in the last 10 years. Also, we observed 12 small family farms ( 20 sows) and 21 individual pig holders (1-3 sows) for biosecurity measures applied. Our results showed that two out of nine large farms raised sheep in the yard of a "shearing" farm, six had dogs and cats present, and all but one did not prevent pigeons from entering. All the farms provided boots and clothes for the visitors, but showering was compulsory only at one farm. A sanitary ford was present in all farms but its maintenance was deficient since in neither farm except one there was no scheduled plan for changing disinfecting solution, or it was changed only when it gets dirty or "when it rains". When an epizootic situation of particular risk arises (e.g., an outbreak of classical swine fever), then special attention is paid to disinfection baths. Four large farms were buying replacements from other farms in Serbia, and three of them were applying the quarantine and controlling the source of the animals. The remaining five farms were buying only imported breeding pigs with 30 days of quarantine and serological testing. Perimetral fence was surrounding all the large farms, but in some, it was in poor condition. Rodent and insect control were generally well applied at all large farms. All the noted biosecurity measures and management practices in small and individual pig holdings are generally lacking or are inconsistently applied. In dense pig populated areas appropriate biosecurity measures, coupled with good producing practice, are crucial to prevent the introduction and the spread of MA within the farm. The epizootic investigation revealed that during the period 2000-2010 the outbreaks of MA were recognized on the territory of 13 municipalities in Vojvodina. The largest number of recognised cases appeared in the municipalities of the Central Backa region, in which the densest pig population was situated. A higher density of pigs increases MA transmission owing to more frequent contacts between the pigs (Lefkowitz et al., 2018). However, the virus may also be introduced by area spread, which includes inter-herd movement of other animal species, people, vehicles, several materials, and air (Bobruskin et al., 1987; Laval et al., 2018).

Epidemiological investigation of the MA outbreaks in large commercial farms and small family farms revealed that in four out of nine cases the purchasing of replacement animals was the source of infection. The introduction of new animals to the farm is considered the major risk factor for MA and replacements are thought to be the most important cause of the introduction of new disease (Kmetiuk et al., 2020). Therefore, the obligatory quarantine measures and serological testing should be conducted when purchasing breeding animals (Dosen et al., 2002). The ADV infection was detected on seven large swine farms of the industrial type, out of which six were involved in vaccination program with live attenuated vaccines against $\mathrm{AD}$. Vaccination failure on these farms was probably due to irregular vaccination of the sows and lack of boosters for piglets and gilts. The observation that clinical ADV was diagnosed in only seven large farms during the past 10 years indicates that infections were subclinical in most of the herds.

According to Dosen et al. (2002), MA infection is present in most swine farms in Vojvodina. The average MA seroprevalence of unvaccinated breeding back yard pigs was estimated at 32.72\% (Pusic et al., 2009), 
suggesting that the swine population in Vojvodina province is enzootically infected with the MA virus. Apparently, vaccination usually induces sufficient clinical protection but does not minimize the spread of ADV (Liu et al., 2019). Feeding animal waste products and slurry to pigs are prohibited in Serbia. Nevertheless, this practice still exists in back yard farming and was a route of introduction of infection in two investigated outbreaks. MA in herbivorous animals was always connected to close contact with pigs on the pasture or while keeping different animal species and pigs within the same premises. ADV infection among sheep housed together with pigs was also described by Ren et al. (2020).

In carnivores, the infection was most often transmitted as a result of the consumption of raw meat, by-products and bones of pigs that had been ill or were latently infected. Beside ingestion, direct contact with pigs was the second most important source of infection for dogs and cats. In three dogs, the documented source of infection was feeding raw lamb by-products after forced slaughter. The swine population in Vojvodina region is enzootically infected with ADV. Individually vaccinated herds are surrounded by non-vaccinated or poorly vaccinated herds and backyard stocks. Occasionally infection was diagnosed in different domestic and wildlife species, but the source of infection for those species was almost in all cases pigs. Voluntary vaccination with live attenuated non-gEdeleted vaccines precludes the serodiagnosis of infected pigs, thus making eradication efforts impossible. Nevertheless, quitting of vaccination on some of the large farms in the region with the high-density pig population without the implementation of strict biosecurity measures is hazardous. The biosecurity and management practices in backyard herds are generally lacking, which makes them a possible threat for large farms. As Aujeszky's disease became a discriminatory factor at the international pig market, it is important to establish regulations regarding disease control and a national or regional Aujeszky's disease eradication program.

\section{Conclusion}

The study of the issues of the epizootic situation of Aujeszky's disease in the territory of the Republic of Kazakhstan led to the following conclusions. In general, the situation with the incidence in the country is controlled and the development, the spread of the virus that causes Aujeszky's disease in the Republic of Kazakhstan is not observed. Over the past few years, the country has seen a sharp decline in the number of cases of Aujeszky's disease among domestic animals: pigs, cattle, and small ruminants. If, as of mid-2017, the incidence of Aujeszky's disease in the Republic of Kazakhstan among pigs and cattle was 92 and 123 cases, respectively, then as of mid-summer of 2020, these figures show 12 and 17 cases of the disease, respectively. The provision of agricultural lands of the Republic, as well as farms and the population with veterinary drugs are at a high level, as well as the skills of workers in the agricultural sector of the Republic of Kazakhstan in the timely use of vaccines against the spread of this disease.

Thus, the analysis of the epizootic situation of Aujeszky's disease in Kazakhstan remains largely open, despite the external controllability of the situation with the spread of this disease. Further research in this area will facilitate understanding of the issue and help assess the severity and danger of the possible spread of the disease in the Republic of Kazakhstan.

\section{References}

Agriculture of the Republic of Kazakhstan. 2020. Available via http://surl.li/eboy (Accessed 13 October 2020).

Allepuz, A., Saez, M., Alba, A., Napp, S. and Casal, J. 2008. Exploratory spatial analysis of Aujeszky disease during four phases of the eradication programme in Catalonia, Spain (2003-2007). Prev. Vet. Med. 86(1-2), 164-175.

Aujeszky Disease (Morbus Aujeszky). 2019. Available via http://webmvc.com/bolezn/livestock/infect/ shared/aujeszky.php (Acessed 18 October 2020).

Boadella, M., Vicente, J., Ruiz-Fons, F., de la Fuente, J. and Gortázar, C. 2012. Effects of culling Eurasian wild boar on the prevalence of Mycobacterium bovis and Aujeszky disease virus. Prev. Vet. Med. 107(3-4), 214-221.

Bobruskin, I.D., Shaǐkhin, S.M., Muratova, M.V., Baranova, L.A. and Severin, E.S. 1987. Allosteric regulation of $\mathrm{Ca} 2+$-calmodulin-dependent phosphodiesterase activity from the bovine brain. Biokhimiia 52(8), 1344-1352.

Brazhko, O.A., Yevlash, A.S., Zavgorodnii, M.P., Kornet, M.M., Brazhko, O.O. and Lagron, A.V. 2019. Basic approaches to the synthesis of pyrrolo[1,2-a]quinolines derivatives: a review. Vopr. Khim. i Khimich. Tekh. 6, 6-16.

Burdinskaya, O.N. 2013. Spectrum of pathogenicity of the pathogen Aujeszky disease. Bull. All-Russ. Res. Inst. Virol. Microbiol. 3, 52-53.

Cheng, Z., Kong, Z., Liu, P., Fu, Z., Zhang, J., Liu, M. and Shang, Y. 2020. Natural infection of a variant pseudorabies virus leads to bovine death in China. Transbound. Emerg. Dis. 67(2), 518-522.

Christensen, J. and Vallières, A. 2016. Scenario tree model for animal disease freedom framed in the OIE context using the example of a generic swine model for Aujeszky disease in commercial swine in Canada. Prev. Vet. Med. 123, 60-70.

Decree of the Minister of Agriculture. 2012. Decree of the minister of agriculture of the Republic of Kazakhstan No. 18-03/128 of March 28, 2012 “On approval of the list of infectious animal diseases subject to restrictive measures or quarantine". 
2012. Available via https://tengrinews.kz/zakon/ pravitelstvo_respubliki_kazahstan_premer ministr_rk/selskoe_hozyaystvo/id-V1200007590/ (Accessed on 22 October 2020).

Dosen, R., Prodanov, J., Petrovi, C.T., Bursa, Ć.V. and Uroševi, Ć.M. 2002. Evaluation of the presence of specific antibodies against Morbus Aujeszky virus in unv accinated swine in Vojvodina province. Biothech. Anim. Husb. 25(5-6), 887-893.

Epizootic Situation. 2018. Epizootic situation on especially dangerous diseases of animals in the world from February 23 to March 2, 2018. 2018. Available via https://fsvps.gov.ru/fsvps/asf/ news/25378.html (Accessed 19 October 2020).

Kmetiuk, L.B., Villalobos, E.M.C., de Souza, M.D.C.C., Lara, H., Machado, F.P., Lipinski, L.C., Santos, A.P.D., Biondo, A.W. and de Barros Filho, I.R. 2020. Serosurvey for Pseudorabies (Aujeszky's disease) in free-range wild boars (Sus scrofa) of Brazil. J. Wildl. Dis. 56(4), 959-961.

Laval, K., Vernejoul, J.B., Van Cleemput, J., Koyuncu, O.O. and Enquist, L.W. 2018. Virulent pseudorabies virus infection induces a specific and lethal systemic inflammatory response in mice. J. Virol. 92, 24; doi:10.1128/JVI.01614-18

Lefkowitz, E.J., Dempsey, D.M., Hendrickson, R.C., Orton, R.J., Siddell, S.G. and Smith, D.B. 2018. Virus taxonomy: the database of the International Committee on Taxonomy of Viruses (ICTV). Nucleic Acids Res. 46(D1), D708-D717.

Liu, Y., Chen, Q., Rao, X., Diao, X., Yang, L., Fang, X. and Hogeveen, H. 2019. An economic assessment of pseudorabies (Aujeszky' disease) elimination on hog farms in China. Prev. Vet. Med. 163, 24-30.

Paes, R.D.C.D.S., Fonseca, A.A., Monteiro, L.A.R.C., Jardim, G.C., Piovezan, U., Herrera, H.M., Mauro, R.A. and Vieira-da-Motta, O. 2013. Serological and molecular investigation of the prevalence of Aujeszky disease in feral swine (Sus scrofa) in the subregions of the Pantanal wetland, Brazil. Vet. Microbiol. 165(3-4), 448-454.

Pomorska-Mól, M., Czyżewska-Dors, E., Kwit, K., Rachubik, J., Lipowski, A. and Pejsak, Z. 2018. Immune response in pigs treated with therapeutic doses of enrofloxacin at the time of vaccination against Aujeszky disease. Res. Vet. Sci. 100, 68-74.

Pusic, I., Duricic, B., Dosen, R., Prodanov, J., Petrovic, T., Bursac, V. and Urosevic, M. 2009. Evaluation of the presence of specific antibodies against Morbus Aujeszky virus in unvaccinated swine in Vojvodina Province. Biotech. Anim. Husban. 25(5-6), 887893.

Ren, J., Wang, H., Zhou, L., Ge, X., Guo, X., Han, J. and Yang, H. 2020. Glycoproteins C and D of PRV strain HB1201 contribute individually to the escape from Bartha-K61 vaccine-induced immunity. Front. Microbiol. 11, 323; doi:10.3389/fmicb.2020.00323
Salinas-Zacarias, I., Guzman-Bautista, E.R., RamírezEstudillo, M.D.C., Chacón-Salinas, R. and VegaLópez, M.A. 2020. Mucosal and systemic immune responses to Aujeszky disease virus (ADV) in early vaccinated piglets. Comp. Immunol. Microbiol. Infect. Dis. 68, 101400; doi:10.1016/j. cimid.2019.101400

Sarmurzina, Z., Bissenova, G., Zakarya, K., Dospaeva, R., Shaikhin, S. and Abzhalelov, A. 2017. Characterization of probiotic strains of Lactobacillus candidates for development of synbiotic product for Kazakh population. J. Pure Appl. Microbiol. 11(1), 151-161.

Shamshedenova, S., Beisenova, R., Rakhymzhan, Z., Zhaznaeva, Z., Syzdykova, N., Tazitdinova, R. and Khanturin, M. 2019. Ecological characteristics of groundwater in rural areas of the Karaganda region. J. Ecol. Eng. 20(11), 67-75.

Silva-Junior, L.C., Fontes, K.F.L.P., Nascimento, S.A., Rodriguez, M.C., Camargos, M.F., Freitas, A.C., Castro, R.S. and Jesus, A.L.S. 2020. Development of a DIVA ELISA for diagnosis of Aujeszky disease using recombinant $\mathrm{gE}$ fused to thioredoxin as antigen. Vet. J. 257, 105448; doi:10.1016/j. tvj1.2020.105448

Tazitdinova, R., Beisenova, R., Saspugayeva, G., Aubakirova, B., Nurgalieva, Z., Zandybai, A., Fakhrudenova, I. and Kurmanbayeva, A. 2018. Changes in the biochemical parameters of rat blood under the combined effect of chronic intoxication with such heavy metals as copper, zinc, arsenic. Advan. Anim. Vet. Sci. 6(11), 492-498.

Uzakov, Y.M., Kaldarbekova, M.A. and Kuznetsova, O.N. 2020. Improved technology for newgeneration Kazakh national meat products. Foods Raw Mater. 8(1), 76-83.

Vaal, T. 2020. The epizootic situation in Republic of Kazakhstan remains stable - the Ministry of Agriculture. Available via https://vlast. $\mathrm{kz} /$ novosti/40312-epizooticeskaa-situacia-vkazahstane-ostaetsa-stabilnoj-msh.html (Accessed 17 October 2020).

Vrublevskaya, V.V., Afanasyev, V.N., Grinevich, A.A., Skarga, Y.Y., Gladyshev, P.P., Ibragimova, S.A., Krylsky, D.V., Dezhurov, S.V. and Morenkov, O.S. 2017a. A sensitive and specific lateral flow assay for rapid detection of antibodies against glycoprotein B of Aujeszky disease virus. J. Virol. Methods 249, $175-80$.

Vrublevskaya, V.V., Afanasyev, V.N., Grinevich, A.A., Skarga, Y.Y., Gladyshev, P.P., Ibragimova, S.A., Krylsky, D.V. and Morenkov, O.S. 2017b. Development of a competitive double antibody lateral flow assay for the detection of antibodies specific to glycoprotein B of Aujeszky disease virus in swine sera. J. Virol. Methods 240, 54-62. 